\title{
Stimulatory Effect of Theophylline on Regulation of Fetal Breathing Movements
}

\author{
IMMANUELA R. MOSS ${ }^{(21)}$ AND EMILE M. SCARPELLI \\ Pediatric Pulmonary Division, Albert Einstein College of Medicine, Bronx, New York, USA
}

\begin{abstract}
Summary
We have performed the fetal $\mathrm{CO}_{2}$ response test on eight mature lambs in utero and have found that theophylline is a respiratory stimulant over a wide range of $\mathrm{PaO}_{2}$ and $\mathrm{pHa}$. Theophylline produces significant increase in slope of $P_{100}, P_{\max }$, and VEq response curves and significant increase in $P_{100}, P_{\max }$, $f$, and VEq responses at $\mathrm{PaCO}_{2}, 65$ torr. It also produces significant lowering of the naturally high fetal absolute threshold to $\mathrm{CO}_{2}$, i.e., $\mathrm{PaCO}_{2}$ at which breathing starts during the $\mathrm{CO}_{2}$ test. "Offset" threshold, i.e., $\mathrm{PaCO}_{2}$ when breathing stops after the test, is the same with and without theophylline and equal to absolute threshold with theophylline. Our studies indicate that: (1) theophylline lowers fetal threshold and increases sensitivity to $\mathrm{CO}_{2} ;(2)$ increased sensitivity is expressed mainly by heightened $\mathrm{P}_{\max }$ (i.e., the equivalent of tidal volume) with some contribution of $f$ particularly at high $\mathrm{PaCO}_{2}$; (3) decreased $\mathrm{CO}_{2}$ threshold is best assessed by determination of absolute threshold rather than the conventional $\mathrm{x}$-axis intercept method; (4) the low offset threshold is consistent with our understanding that arousal is a requisite for generation and maintenance of fetal breathing; (5) theophylline is as effective a respiratory stimulant during fetal acidemia and hypoxemia as it is under normal conditions; and (6) a number of serious reservations must be held regarding use of theophylline during low $\mathrm{pHa}$, low $\mathrm{PaO}_{2}$ states.
\end{abstract}

\section{Speculation}

Theophylline, which is shown to be an effective respiratory stimulant in the ovine fetus, activates central respiratory units by a process of recruitment analogous to that of other inputs, e.g., somatosensory and chemoreceptor afferents. Changes in the state of respiratory center arousal, including its return to natural quiescence with apnea when inputs are withdrawn, can be assessed by the fetal $\mathrm{CO}_{2}$ test and bear on the phenomena of onset of breathing at birth, neonatal apnea, and sudden infant death.

Rationale for the use of theophylline to reduce incidence and severity of apnea of prematurity $(3,17,19)$ is its presumptive effect on activation of the central nervous system and excitation of physiologic respiratory reflexes (9). However, few controlled studies have been attempted to quantify the effect of theophylline on respiratory regulation, and some results have been contradictory. Whereas it is reported that theophylline increases the response to hypoxia but has no effect on $\mathrm{CO}_{2}$ response in adults (10), it has also been suggested that $\mathrm{CO}_{2}$ sensitivity increases and $\mathrm{CO}_{2}$ threshold is lowered when theophylline is given to babies (7).

We have examined the effect of theophylline on regulation of breathing in our lamb fetal model (11), which offers the following advantages. Because the fetus is normally apneic for extended periods of time, one can assess directly the effect of theophylline on the onset of fetal breathing and on absolute threshold to $\mathrm{CO}_{2}$. In addition, the fetal $\mathrm{CO}_{2}$ test (11) can be used to evaluate the effect of theophylline on sensitivity and extrapolated threshold to $\mathrm{CO}_{2}$ from the $\mathrm{CO}_{2}$ response curves. At the serum levels achieved in this study, theophylline did not initiate fetal breathing move- ments before elevation of $\mathrm{PaCO}_{2}$. However, it did increase sensitivity to $\mathrm{CO}_{2}$ and lower the naturally high $\mathrm{CO}_{2}$ threshold of the mature fetus in utero.

\section{MATERIALS AND METHODS}

The animal preparation and method for estimation of respiratory control in the fetus have been described in detail in a previous report (11). In summary, experiments were carried out on eight pregnant sheep near term (140 to 144 days). Under local anesthesia, an endotracheal tube was inserted through a tracheostomy in the ewe and was used for $\mathrm{CO}_{2}$ rebreathing. The uterus was exteriorized through an abdominal incision under spinal anesthesia and was kept moist and warm throughout the experiment. The fetal neck was marsupialized to the uterine wall under local anesthesia, and the fetal trachea and carotid artery were cannulated for measurement of intratracheal pressure (ITP), for recording of fetal arterial pressure and heart rate and measurement of $\mathrm{pHa}, \mathrm{PaCO}_{2}$, and $\mathrm{PaO}_{2}$. The fetal tracheal cannula was attached directly to a Statham P23d transducer (closed, liquid-filled system) from which ITP was recorded directly on a Narco BioSystems eight channel polygraph (sensitivity $<0.5 \mathrm{~cm} \mathrm{H}_{2} \mathrm{O}$ pressure). There was virtually no loss of amniotic fluid during the marsupialization procedure, and the fetus remained inside the uterus throughout the study.

Fetal $\mathrm{CO}_{2}$ responsivity was established by the fetal $\mathrm{CO}_{2}$ test (11), in which fetal breathing response is measured during increasing fetal $\mathrm{PaCO}_{2}$, which is brought about by $\mathrm{CO}_{2}$ rebreathing in the ewe. All fetuses in this study were apneic before fetal $\mathrm{CO}_{2}$ tests. Generated fetal breathing movements were made against a closed trachea so that flow of normal fetal pulmonary fluid was not a factor during the study. In addition, because the lungs are normally filled with pulmonary fluid at about functional residual capacity and because fluid volume is not expected to change significantly during episodes of induced fetal breathing $(11,15)$, we conclude that the lungs were at resting volume during the tests and that fluid compression was not a factor (11).

One-half to $1 \mathrm{hr}$ after completion of surgical preparation and observation of the fetus to ensure normal blood pressure and heart rate, the ewe was made to rebreathe $7 \% \mathrm{CO}_{2}-93 \% \quad \mathrm{O}_{2}$ in our modification (11) of the Read rebreathing method (13, 14). The fetal breathing response to $\mathrm{CO}_{2}$ was quantified as follows: (1) $\mathrm{P}_{100}$ (torr) was defined as the ITP deflection during the first $100 \mathrm{msec}$ of an inspiratory effort and was considered to represent respiratory drive; (2) $\mathrm{P}_{\max }$ (torr) was defined as the maximal ITP per breath and was considered equivalent to tidal volume; (3) breathing frequency ( $\mathrm{f}, \mathrm{min}^{-1}$ ), and (4) ventilation equivalent (VEq) was defined as the sum of peak intratracheal pressure efforts for $1 \mathrm{~min}$ $\left(\Sigma\right.$ torr $\left.\min ^{-1}\right)$. After the control fetal $\mathrm{CO}_{2}$ test and when fetal $\mathrm{PaCO}_{2}$ had returned to pretest levels, theophylline was administered to the ewe at a dose of $\mathrm{H} 5 \mathrm{mg} / \mathrm{kg}$ aminophylline (according to estimated body weight, $\pm 5 \mathrm{~kg}$, of the prestudy pregnant ewe) by IV infusion for $20 \mathrm{~min}$. Serum theophylline levels were determined immediately before the $\mathrm{CO}_{2}$ test, both in the ewe and fetus, by the theophylline-specific enzyme mediated immunoassay (Syva, Palo Alto, CA). Sensitivity of the assay in our laboratory 
Table 1. Effects of theophylline on fetal heart rate and blood pressure and on $\mathrm{PaCO}_{2}$ measurements during fetal CO $\mathrm{O}_{2}$ tests

\begin{tabular}{|c|c|c|c|c|}
\hline & $\begin{array}{l}\text { Heart rate } \\
\left(\min ^{-1}\right)\end{array}$ & $\begin{array}{l}\text { Mean arterial } \\
\text { pressure (torr) }\end{array}$ & $\begin{array}{c}\mathrm{PaCO}_{2}{ }^{1} \\
\text { (torr) }\end{array}$ & $\begin{array}{c}\Delta \mathrm{PaCO}_{2}{ }^{2} \\
\text { (torr) }\end{array}$ \\
\hline Control $(\mathrm{n}=8)^{3}$ & $176.3 \pm 13.3^{4}$ & $62.0 \pm 2.5$ & $46.1 \pm 4.4$ & $+21.4 \pm 3.2$ \\
\hline Theophylline $(\mathrm{n}=11)$ & $173.6 \pm 14.9$ & $59.9 \pm 2.6$ & $44.8 \pm 3.3$ & $+18.8 \pm 1.6$ \\
\hline Difference $^{5}$ & NS & NS & NS & NS \\
\hline
\end{tabular}

${ }^{1}$ Fetal $\mathrm{PaCO}_{2} 1 \mathrm{~min}$ after the start of fetal $\mathrm{CO}_{2}$ test.

${ }^{2}$ Increase of fetal $\mathrm{PaCO}_{2}$ during fetal $\mathrm{CO}_{2}$ test.

${ }^{3} n=$ number of measurements.

${ }^{4}$ Mean \pm S.E.

${ }^{5}$ By paired comparison statistical analysis and Student's $t$ test; NS $=$ not significant $(P>0.05)$.

is 2.5 to $20 \mu \mathrm{g} / \mathrm{ml}$ with an intra-assay coefficient for variation of $4 \%$. In one fetus (fetus 8 ), the $\mathrm{CO}_{2}$ test was repeated once and in another (fetus 4), it was repeated twice after $\mathrm{PaCO}_{2}$ had returned to control after the preceding test. $\mathrm{P}_{100}, \mathrm{P}_{\max }, \mathrm{f}$, and VEq were used to describe fetal breathing response to $\mathrm{PaCO}_{2}$ both when $\mathrm{CO}_{2}$ was the sole respiratory stimulus and when it was combined with theophylline. Results were expressed in terms of $\mathrm{P}_{100}-\mathrm{PCO}_{2}, \mathrm{P}_{\max }-$ $\mathrm{PCO}_{2}$, f- $\mathrm{PCO}_{2}$, and VEq- $\mathrm{PCO}_{2}$ response curves, from which slopes and $\mathrm{x}$-axis intercepts as well as specific values at $\mathrm{PaCO}_{2}$ of 65 torr were used for statistical analysis. $\mathrm{PaCO}_{2} 65$ torr, for fetuses that did not achieve this level during the $\mathrm{CO}_{2}$ test, was determined by extrapolation from the slope of the $\mathrm{CO}_{2}$ response. This assumes that the fetus' response would continue along the linear plot if $\mathrm{PaCO}_{2}$ had been allowed to increase to 65 torr.

\section{RESULTS}

Serum levels of theophylline at the time of the fetal $\mathrm{CO}_{2}$ tests were $11.6 \pm 2.0 \mu \mathrm{g} / \mathrm{ml}(\overline{\mathrm{x}} \pm \mathrm{S}$.E. $)$ in the ewe and $5.9 \pm 2.1 \mu \mathrm{g} / \mathrm{ml}$ in the fetus $(n=11)$. As shown in Table 1, theophylline did not result in significant changes of fetal heart rate and blood pressure. One min after the start of the test, fetal $\mathrm{PaCO}_{2}$ was $46.1 \pm 4.4$ torr at control and $44.8 \pm 3.3$ torr after theophylline infusion; the difference is not significant. $\mathrm{PaCO}_{2}$ increased during the test by $21.4 \pm 3.2$ torr at control and by $18.8 \pm 1.6$ torr after theophylline; the difference between the two is not significant. These results are summarized in Table 1.

The relationship between fetal $\mathrm{PaO}_{2}$ and $\mathrm{pHa} 1$ min into the $\mathrm{CO}_{2}$ test is shown in Figure 1. The correlation coefficient $(0.76)$ is significant $(P<0.01)$, whereas the differences in each parameter between control and theophylline are not. The variation of $\mathrm{PaO}_{2}$ and $\mathrm{pHa}$ among fetuses was related both to their individual response to the surgical procedure and to the time after preparation at which the $\mathrm{CO}_{2}$ tests were done. However, heart rate and rhythm and blood pressure were normal at the levels given in Table 1; these parameters did not change during the course of the experiments. Fetal $\mathrm{PaO}_{2}$ increased significantly $(P<0.01)$ during the $\mathrm{CO}_{2}$ test by $4.4 \pm 1.0$ torr (control) and by $3.9 \pm 0.7$ torr (theophylline), and the difference between the two is not significant. Because of the wide range of $\mathrm{PaO}_{2}-\mathrm{pHa}$ among fetuses, we compared the $\mathrm{CO}_{2}$ responses of the acidemic subjects $(\mathrm{pHa}<7.2)$ with those of fetuses with $\mathrm{pHa}>7.24$, as shown in Figure 1 (boxed groups). Although responses of the acidemic group tended to be slightly lower, there was no significant difference between these two groups. There was no relationship between the level of theophylline and the magnitude of fetal breathing response in individual experiments.

Theophylline alone did not initiate breathing movements in any of the fetuses before and between the $\mathrm{CO}_{2}$ tests. The effects of theophylline on $\mathrm{P}_{100}, \mathrm{P}_{\max }, \mathrm{f}$, and $\mathrm{VEq}$ during the fetal $\mathrm{CO}_{2}$ test are shown in Figure 2 in which the response curves from a single experiment are presented. The effects of theophylline on slope, $x$ axis intercept (i.e., extrapolated $\mathrm{CO}_{2}$ threshold), and response at $\mathrm{PaCO}_{2} 65$ torr are summarized in Table 2 as the differences between responses at control and after theophylline. Theophylline produced a significant increase both in the slopes of the $\mathrm{P}_{100}-\mathrm{PCO}_{2}$, $\mathrm{P}_{\max }-\mathrm{PCO}_{2}$, and VEq- $\mathrm{PCO}_{2}$ response curves and in the $\mathrm{P}_{100}, \mathrm{P}_{\max }$,

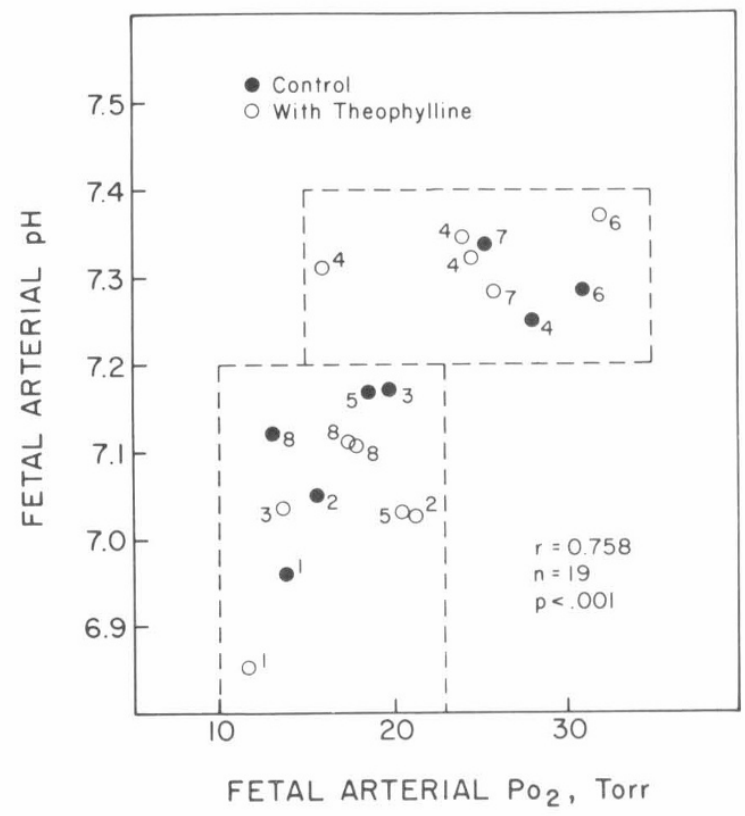

Fig. 1. The relationship between fetal $\mathrm{PaO}_{2}$ and $\mathrm{pHa} 1 \mathrm{~min}$ after the start of fetal $\mathrm{CO}_{2}$ test with and without theophylline.

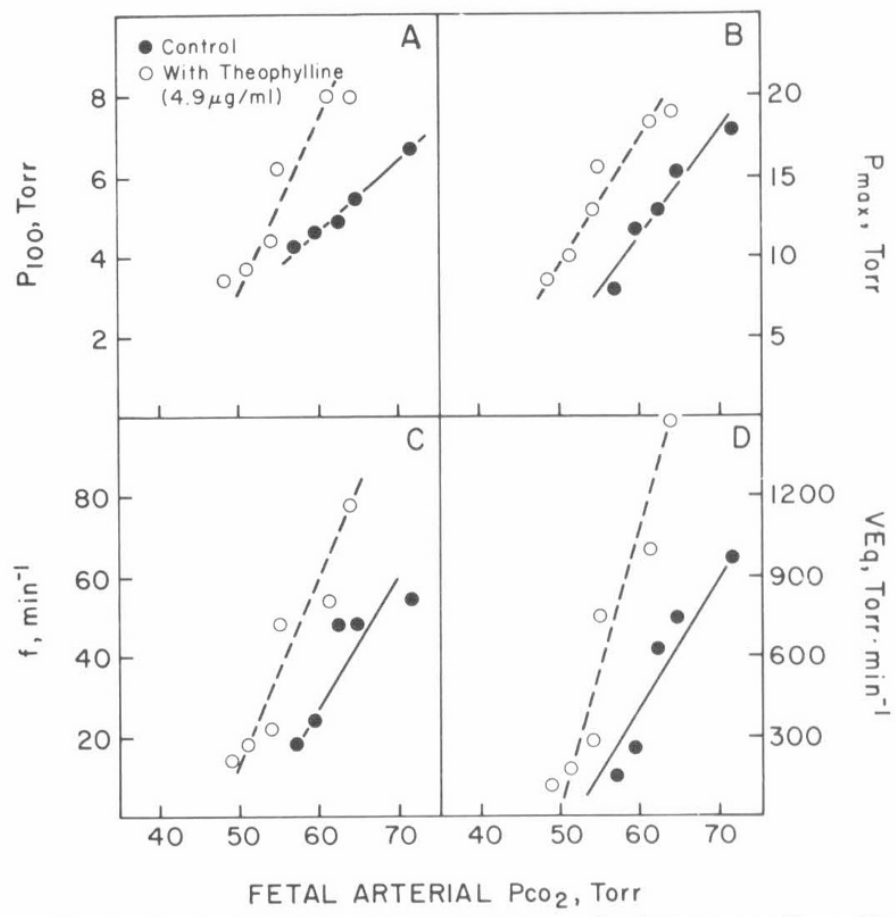

Fig. 2. Respiratory drive $\left(\mathrm{P}_{100} ; A\right)$, intratracheal pressure $\left(\mathrm{P}_{\max } ; B\right)$, breathing frequency ( $\mathrm{f} ; C$ ) and ventilation equivalent (VEq; $D$ ) responses to fetal $\mathrm{PaCO}_{2}$ in response to $\mathrm{CO}_{2}$ alone and to $\mathrm{CO}_{2}$ combined with theophylline. Data are from a single experiment (see text). 
Table 2. Effects of theophylline on $\mathrm{CO}_{2}$ response in fetal lambs in utero

\begin{tabular}{lccc}
\hline & $\mathrm{S}^{1}$ & $\mathrm{I}$ & 65 \\
\hline $\mathrm{P}_{100}$ & $0.3 \pm 0.1^{2}$ & $1.5 \pm 9.7$ & $10.4 \pm 2.9$ \\
& $P<0.025$ & $\mathrm{NS}$ & $P<0.005$ \\
$\mathrm{P}_{\max }$ & $0.9 \pm 0.4$ & $0.6 \pm 6.4$ & $22.1 \pm 3.7$ \\
& $P<0.050$ & $\mathrm{NS}$ & $P<0.001$ \\
$\mathrm{f}$ & $1.1 \pm 0.7$ & $-18.4 \pm 20.4$ & $50.7 \pm 18.9$ \\
& $\mathrm{NS}$ & $\mathrm{NS}$ & $P<0.025$ \\
$\mathrm{VEq}$ & $77.2 \pm 22.7$ & $-2.4 \pm 7.3$ & $1799.3 \pm 582.4$ \\
& $P<0.010$ & $\mathrm{NS}$ & $P<0.025$ \\
\hline
\end{tabular}

${ }^{1} \mathrm{~S}=$ slope, i.e., $\mathrm{CO}_{2}$ sensitivity in torr $\cdot \mathrm{PCO}_{2}$ torr ${ }^{-1}$ for $\mathrm{P}_{100}$ and $\mathrm{P}_{\max }$, in $\mathrm{min}^{-1} \cdot \mathrm{PCO}_{2} \operatorname{torr}^{-1}$ for $f$, and in torr $/ \mathrm{min} \cdot \mathrm{PCO}_{2} \operatorname{torr}^{-1}$ for VEq; $\mathrm{I}=\mathrm{x}$-axis intercept, i.e., $\mathrm{CO}_{2}$ threshold in torr $\mathrm{PaCO}_{2} ; 65=$ a selected fetal $\mathrm{PaCO}_{2}$ level at which $\mathrm{P}_{100}, \mathrm{P}_{\max }, f$, and $\mathrm{VEq}$ were calculated specifically.

${ }^{2}$ Mean \pm S.E. of the difference between responses to $\mathrm{CO}_{2}$ alone and to $\mathrm{CO}_{2}$ combined with theophylline $(n=11)$. Statistics are based on paired comparison analysis and student's $t$ test.

and VEq responses at $\mathrm{PaCO}_{2} 65$ torr. Although the slope of the f$\mathrm{PCO}_{2}$ response was higher than control after theophylline, the change was not significant, in contrast to the significant increase of $\mathrm{f}$ at $\mathrm{PaCO}_{2} 65$ torr.

Whereas in the experiment shown in Figure 2 the $x$-axis intercepts of $\mathrm{P}_{100}, \mathrm{P}_{\max }, \mathrm{f}$, and VEq curves are shifted to the left with theophylline, these extrapolations were variable among experiments, so that the overall result was that theophylline did not change the intercept significantly (Table 2). Because determination of $\mathrm{CO}_{2}$ threshold by this method is indirect, we also measured fetal $\mathrm{PaCO}_{2}$ directly near the time at which the fetus started breathing during the $\mathrm{CO}_{2}$ test. This value may be taken as an index of absolute ("onset") fetal threshold to $\mathrm{CO}_{2}$ (11). We found that, at control, the fetuses started breathing at $\mathrm{PaCO}_{2}$ of $55.9 \pm$ 2.5 torr $(n=8)$, and after theophylline, they started breathing at $\mathrm{PaCO}_{2}$ of $46.4 \pm 2.9$ torr $(n=11)$. When calculated by paired comparison analysis, the difference between absolute thresholds to $\mathrm{CO}_{2}$ is significant $(P<0.005)$.

All fetuses stopped breathing within 1 to $3 \mathrm{~min}$ after the $\mathrm{CO}_{2}$ test, at which time fetal blood samples were drawn and $\mathrm{PaCO}_{2}$ threshold for offset of breathing was determined. At control, this threshold was $46.8 \pm 3.1$ torr $(n=4)$, and with theophylline, it was $45.7 \pm 2.4$ torr $(n=5)$. The difference between the two is not significant, nor is the difference between these offset thresholds and the absolute (onset) threshold with theophylline.

\section{DISCUSSION}

Our studies show that theophylline increases central responsiveness to $\mathrm{CO}_{2}$ and thus may be classified as a respiratory stimulant of the fetus over a wide range of $\mathrm{PaO}_{2}$ and $\mathrm{pHa}$. However, this designation of theophylline should include the following qualifications: (1) because theophylline is a general metabolic stimulant that accelerates cerebral metabolism, it may be particularly harmful in the presence of fetal hypoxemia (18); (2) because methylation to caffeine is a significant pathway of theophylline metabolism in the perinatal subject $(2,4)$, the cumulative effect of the two drugs may increase toxicity; (3) although theophylline is effective at low $\mathrm{pH}$, the combined effects of methyl xanthines and acidemia on cerebral, cardiac, and gastrointestinal function need to be taken into account. Observation of heart rate, blood pressure, and amniotic fluid appearance during the course of our studies gave no sign of toxic response to theophylline. Clearly, more direct and extended assessment is needed.

Cosmi (6) has reported that theophylline infusion to the ewe results in generation of fetal breathing movements; the quantities administered were two to three times larger than those of our experiments. In addition, a number of investigators have reported successful treatment of apnea of prematurity with theophylline infusion to the infant $(1,3,7-9,17,19)$. The serum levels achieved in infants, when reported, were comparable to or larger than those produced in our fetuses. In contrast to our fetuses in utero, however, the patients were subject to the usual environmental stimuli of the nursery, which are important activators of perinatal breathing $(5,16)$. Thus, we would suggest that theophylline levels in our studies were too low to induce spontaneous breathing movements in the previously apneic fetus, but that respiratory control was affected to the extent that $\mathrm{CO}_{2}$ threshold and responsivity were facilitated. As $\mathrm{PaCO}_{2}$ was increased during the $\mathrm{CO}_{2}$ test, the lowered threshold and increased sensitivity became apparent. This state would correspond to stage 1 in the activation of central respiratory units of the apneic fetus, in which recruitment of respiratory neurons has not yet reached the level needed for activation of inspiratory-facilitatory neurons, as discussed previously (5). Because we have no data on possible conversion of theophylline to caffeine in the lamb fetus, we cannot speculate on the possible role of the latter in stimulating respiratory control

We have described in a previous report (11) the ovine animal model for study of generation and regulation of fetal breathing. This model offers the advantages of: (1) producing linear increase of fetal $\mathrm{PaCO}_{2}$ during maternal rebreathing; (2) assessment of respiratory drive from measurements of ITP; (3) determination of ventilation analogue (VEq) from measurements of $P_{\max }$ and $f$; and (4) avoiding the complications of changes in lung mechanics during the test period. Whereas $\mathrm{PaO}_{2}$ did not change significantly during the fetal $\mathrm{CO}_{2}$ test in our previous study (11), it did increase in the present experiments. The increase, however, was the same both with and without theophylline so that $\mathrm{PaO}_{2}$ can be excluded as a cause for the increased $\mathrm{CO}_{2}$ responsiveness with the drug.

The effect of theophylline on fetal breathing may be quantified in several ways. It is evident from the changes in slope of $\mathrm{P}_{100^{-}}$ $\mathrm{PCO}_{2}, \mathrm{P}_{\max }-\mathrm{PCO}_{2}$, and VEq- $\mathrm{PCO}_{2}$ response curves that theophylline does increase $\mathrm{CO}_{2}$ sensitivity. Because the apparent increase of $\mathrm{f}$ $\mathrm{PCO}_{2}$ slope was not significant, we may conclude that augmentation of $\mathrm{VEq}-\mathrm{PCO}_{2}$ slope was due primarily to increased $\mathrm{P}_{\max }$, which is the equivalent of tidal volume (11). However, facilitation of $\mathrm{f}$ cannot be excluded because, for a given $\mathrm{PaCO}_{2}$ (e.g., 65 torr), teophylline produces a significant increase of $\mathrm{P}_{100}, \mathrm{P}_{\max }, \mathrm{VEq}$, and $f$. Whether or not such changes in $f$ are related to recruitment of inspiratory-expiratory units by mechanisms similar to those described in another report (5) remains speculative at present.

The most complicated aspect of the breathing response to theophylline is assessment of its effect on threshold to $\mathrm{CO}_{2}$. Inasmuch as the fetuses of this study were apneic before the $\mathrm{CO}_{2}$ test, we were able to determine $\mathrm{CO}_{2}$ threshold both by extrapolation of the response curves to the $\mathrm{x}$-axis (extrapolated threshold) and by direct measurement of $\mathrm{PaCO}_{2}$ near the time that breathing movements began (absolute threshold). We compared absolute threshold at control (before theophylline) to both absolute and extrapolated thresholds of apneic fetuses in our previous study (11) and found no difference among any of these; mean values ranged from $\mathrm{PaCO}_{2} 52.7$ to 55.9 torr. This confirms our conclusion (11) that $\mathrm{CO}_{2}$ threshold in the apneic fetus is high and that normal fetal $\mathrm{PaCO}_{2}$ is in itself not a stimulus to breathing. In contrast, the absolute threshold with theophylline was significantly lower than all $\mathrm{CO}_{2}$ thresholds of previously apneic fetuses, but it was not different from the extrapolated threshold of fetuses that had been breathing spontaneously before the $\mathrm{CO}_{2}$ test (11). This indicates that, in terms of $\mathrm{CO}_{2}$ responsiveness, the effect of theophylline is analogous to that of other stimuli $(5,11)$ that may produce arousal and activation of central respiratory neurons.

Our finding that theophylline effect was not apparent by comparison of extrapolated thresholds before and after infusion of the drug reflects possible errors inherent in the $x$-axis intercept method when applied to the previously apneic subject. It suggests that the rate of increase of respiration from the state of apnea has at least two slopes which may be concealed in standard analysis. For spontaneously breathing fetuses, the difficulty is the same as that encountered when the test is applied to air-breathing subjects, viz., the curve may not in fact intercept the $x$-axis from a linear plot (12). A real limitation is the number of $\mathrm{PaCO}_{2}$ determinations that can be made during the test. Continuous recording would be 
preferred, and it is clear that, under any circumstances, "curves" based on only two determinations (7) may compromise reliability of the test. However, when the fetus is apneic, absolute threshold, which is determined easily during the $\mathrm{CO}_{2}$ test, should be taken as the definitive threshold.

The offset $\mathrm{CO}_{2}$ threshold before and after theophylline was the same as both the theophylline-induced absolute (onset) threshold and the extrapolated (onset) threshold of spontaneously breathing fetuses of our previous study (11). Because all these thresholds were lower than the absolute (onset) threshold of control apneic fetuses, it is conceivable that chemical and pharmacologic stimuli (i.e., $\mathrm{CO}_{2}$ and theophylline) act similarly to natural arousal (i.e., spontaneous breathing in utero) in exerting an excitatory effect on the respiratory control system located in the brainstem. The high absolute threshold to $\mathrm{CO}_{2}$ of control apneic fetuses reflects a less excited state of respiratory control which may be of relevance to clinical conditions, such as apnea of prematurity and sudden infant death syndrome. Additional studies are required, including monitoring of cortical activity and function of central respiratory units.

\section{REFERENCES AND NOTES}

1. Aranda, J. V., Gorman, W., Bergsteinsson, H., and Gunn, T.: Efficacy of caffeine in treatment of apnea in the low birth-weight infant. J. Pediatr., 90: 467 (1977).

2. Aranda, J. V., Louridas, A. T., Vitullo, B. B., Thom, P., Aldridge, A., and Haber. R.: Metabolism of theophylline to caffeine in human fetal liver. Science (Wash. D. C.), 206: 1319 (1979).

3. Bednarek, F. J., and Roloff, D. W.: Treatment of apnea of prematurity with aminophylline. Pediatrics, 58: 335 (1976).

4. Bory, C., Baltassat, P., Porthault, M., Bethenod, M., Frederich, A., and Aranda, J. V.: Metabolism of theophylline to caffeine in premature newborn infants. J. Pediatr., 94: 988 (1979)

5. Condorelli, S., and Scarpelli, E. M.: Somatic respiratory reflex and onset of regular breathing movements in the lamb fetus in utero. Pediatr. Res., 9: 879 (1975).

6. Cosmi, E. V.: Beta-stimulants and analogues in obstetrical anesthesia. Interna- tional Conference: Survival of the Newborn Infant. Rome, May 2-5, 1978.

7. Davi, M. J., Sankaran, K., Simons, K. J., Simons, F. E. R., Seshia, M. M., and Rigatto, H.: Physiologic changes induced by theophylline in the treatment of apnea in preterm infants. J. Pediatr., 92: 91 (1978)

8. Gerhardt, T., McCarthy, J., and Bancalari. E.: Aminophylline therapy for idiopathic apnea in premature infants: effects on lung function. Pediatrics, 62: 801 (1978).

9. Kattwinkel, J.: Neonatal apnea: pathogenesis and therapy. J. Pediatr., 90: 342 (1977).

10. Lakshminarayan, S., Sahn, S. A.. and Weil, J. V.: Effect of aminophylline on ventilatory responses in normal man. Am. Rev. Respir. Dis., 117: 33 (1978).

11. Moss, I. R., and Scarpelli, E. M.: Generation and regulation of breathing in utero: fetal $\mathrm{CO}_{2}$ response test. J. Appl. Physiol., 47: 527 (1979).

12. Nielsen, M., and Smith, H.: Studies on the regulation of respiration in acute hypoxia. Acta Physiol. Scand., 24: 293 (1951).

13. Read, D. J.C.: A clinical method for assessing the ventilatory response to carbon dioxide. Australas. Ann. Med., 16: 20 (1967)

14. Read, D. J. C., and Leigh, J. Blood-brain tissue $\mathrm{PCO}_{2}$ relationships and ventilation during rebreathing. J. Appl. Physiol., 23: 53 (1967).

15. Scarpelli, E. M., Condorelli, S., and Cosmi, E. V.: Lamb fetal pulmonary fluid. I. Validation and significance of method for determination of volume and volume change. Pediatr. Res., 9: 190 (1975).

16. Scarpelli, E. M., and Moss, I. R.: Control of fetal and neonatal breathing and its disturbances. Clin. Chest Med., 1: 145 (1980).

17. Shannon, D. C., Gotay, F., Stein, I. M., Rogers, M. C., Todres, I. D., and Moylan, F. M. B.: Prevention of apnea and bradycardia in low birthweight infants. Pediatrics, 55: 589 (1975)

18. Thurston, J. H., Hauhart, R. E., and Dirgo, J. A.: Aminophylline increases cerebral metabolic rate and decreases anoxic survival in young mice. Science (Wash. D. C.), 201: 649 (1978).

19. Uauy, R., Shapiro, D. L., Smith, B., and Warshaw, J. B.: Treatment of severe apnea in prematures with orally administered theophylline. Pediatrics, 55: 585 (1975).

20. Dr. Moss is a recipient of a Research Career Development Award from the National Heart, Lung and Blood Institute, National Institutes of Health.

21. Requests for reprints should be addressed to: Dr. Immanuela R. Moss, Pediatric Pulmonary Division, Albert Einstein College of Medicine, 1300 Morris Park Avenue, Bronx, New York 10461 (USA).

22. This research was supported by a grant from the National Heart, Lung and Blood Institute, National Institutes of Health. HL 23995.

23. Received for publication May 2, 1980.

24. Accepted for publication September 16, 1980. 